\title{
Identification of constituent herbs in ginseng decoctions by DNA markers
}

\author{
Yat-Tung Lo' ${ }^{1}$, Ming Li ${ }^{2}$ and Pang-Chui Shaw ${ }^{1,2^{*}}$
}

\begin{abstract}
Background: DNA in herbal decoctions is usually fragmented by extensive boiling and is usually regarded as unsuitable for molecular authentication. This study aims to evaluate the feasibility for molecular authentication methods by multiplex polymerase chain reaction (PCR) and DNA sequencing for decoctions.

Methods: The DNA extraction procedure, sample pulverization and boiling time were examined in (1) single herb decoction with Panax ginseng ("ginseng") or P. quinquefolius ("American ginseng"), (2) decoctions of two classical ginseng prescriptions of five herbal materials (Aconitum carmichaeli, Atractylodes macrocephala, P. ginseng, Glycyrrhiza uralensis and Zingiber officinale) and (3) a commercial ready-to-serve ginseng soup. Primers were designed from 26S-18S, ITS2 and trnH-psbA region, with DNA sequences obtained from GenBank. Multiplex PCR was also employed in ginseng or American ginseng decoctions to differentiate between these two herbs.
\end{abstract}

Results: All six herbal species tested in this study could be identified in decoctions. We had four main observations: (1) sample pulverization before boiling improved PCR detection; (2) prolonged boiling increased the DNA concentration but decreased the intactness of DNA fragments; (3) ginseng could be differentiated from American ginseng by multiplex PCR; (4) identification of individual herbs in multi-herb decoctions with prolonged boiling time of 180 min could be achieved.

Conclusions: DNA could be amplified from extensively boiled ginseng decoctions, multi-herb decoctions and commercial soup although DNA degradation was critical to successful PCR.

Keywords: Ginseng, Decoction, Molecular authentication, DNA marker, Multiplex PCR, DNA sequencing

\section{Background}

Intentional or inadvertent adulteration of herbal products, including health food and dietary supplements, can cause adverse effects or even poisoning [1-6]. For instance, misidentification of the toxic vine Gelsemium elegans as Mussaenda pubescens (an ingredient of Chinese health drinks) caused two poisoning cases in Hong Kong [3]. Adulteration of the anti-inflammatory agent Stephania tetrandra by the toxic herb Aristolochia fangchi led to more than 100 cases of kidney failure and urothelial carcinoma in Belgium [4]. Adulterants have also been found in expensive herbs such as Panax quinquefolius [7], and materials from endangered species such as the

\footnotetext{
*Correspondence: pcshaw@cuhk.edu.hk
'School of Life Sciences, The Chinese University of Hong Kong, Shatin, N.T.,

*Correspondence: pcshaw@cuhk.edu.hk
'School of Life Sciences, The Chinese University of Hong Kong, Shatin, N.T., Hong Kong, China

${ }^{2}$ State Key Laboratory of Phytochemistry and Plant Resources in West China
(CUHK), Institute of Chinese Medicine, The Chinese University of Hong Kong

${ }^{2}$ State Key Laboratory of Phytochemistry and Plant Resources in West China
(CUHK), Institute of Chinese Medicine, The Chinese University of Hong Kong, Shatin, N.T., Hong Kong, China
}

horn of Saiga tatarica [8]. Therefore, reliable and effective methods of authentication are crucial for the quality control of herbal materials and their products.

Authentication of highly processed herbal materials is difficult. Examples include comparison of the morphological and microscopic characteristics of easily confused herbs and their dregs after boiling $[9,10]$. The approaches described could be useful, but the dregs in a decoction are usually discarded before consumption. Authentication is also possible by chemical or physical analyses such as high performance liquid chromatography [11], mass spectrometry [12] and nuclear magnetic resonance [13]. However, the chemical constituents in decoction may be altered by physiological conditions, harvesting period, storage and boiling conditions of the herbs involved. Such methods also make differentiation between related species quite difficult owing to their similar chemical profiles and demanding sophisticated instrumentation [14].

( Biomed Central

(c) 2015 Lo et al.; licensee BioMed Central. This is an Open Access article distributed under the terms of the Creative Commons Attribution License (http://creativecommons.org/licenses/by/4.0), which permits unrestricted use, distribution, and reproduction in any medium, provided the original work is properly credited. The Creative Commons Public Domain Dedication waiver (http://creativecommons.org/publicdomain/zero/1.0/) applies to the data made available in this article unless otherwise stated. 
Since the 1990s, molecular methods have been used for authentication. There have been reports of using internal transcribed spacer 2 (ITS2) region to distinguish Lycium barbarum from its various types [15]; polymerase chain reaction (PCR) fragment length polymorphisms in the 3 ' untranslated region of cDNA sequences to identify the root of Astragalus membranaceus [16]; DNA microarrays to authenticate ginseng drugs [17]; and PCR based method to characterize alfalfa and red clover [18]. Molecular methods and employment of DNA barcodes can produce accurate, reliable and sensitive results $[19,20]$.

China was the first country to recognize molecular methods as a legal basis for authentication of crude herbal drugs, including Fritillaria unibracteata [21] and Zaocys dhumnades [22]. The future of molecular authentication is promising, even with DNA degradation during processing. For instance, molecular authentication of meats in processed food had been reported [23-25] and short microsatellite DNA fragments could be obtained from a highly processed medicinal product prepared from the skin of Equus asinus [26]. A recent report described using the ribosomal external transcribed spacer region to authenticate ginseng products such as tea and red ginseng extract [7]. However, how these products were processed and whether they contained ginseng residues was not mentioned.

Identification of herbal ingredients in decoctions is highly significant because this method will extend molecular authentication of herbal products. This method may also be useful for law enforcement authorities and may benefit consumers. Thus this study aims to evaluate the feasibility for molecular authentication methods by PCR and DNA sequencing for decoctions. We employed a single herb decoction with $P$. ginseng ("ginseng") or $P$. quinquefolius ("American ginseng"), decoctions of two classical ginseng prescriptions with multiple herbal materials, and a commercial ready-to-serve ginseng soup to investigate the availability of DNA for molecular authentication. Then, we identified the DNA in the decoctions by multiplex PCR and DNA sequencing.

\section{Methods}

\section{Samples}

Herbal materials were purchased in a herbal shop (Zisun Pharmaceutical Ltd., Guangzhou, China). All herbal samples were identified with their organoleptic characteristics by Dr. David Tai-Wai Lau, Curator of the Shui-Ying Hu Herbarium, School of Life Sciences, The Chinese University of Hong Kong according to the Pharmacopoeia of the People's Republic of China (2010 edition) [22] and confirmed by DNA sequencing. All authentic voucher specimens were deposited in the Institute of Chinese Medicine, The Chinese University of Hong Kong (Table 1).
Dust and soil on the surface of samples were removed by cleaning with water. These herbs were prepared for decoctions. A commercial ready-to-serve ginseng soup, Korean Ginseng Chicken Stew (Harim, Korea; product code: 8801492307002; voucher code: T3475), which claimed to contain $P$. ginseng on the label, was purchased from a local supermarket.

\section{Preparation of decoctions}

A single herb decoction was prepared from $P$. ginseng or $P$. quinquefolius. Each herb was divided into two equal portions. One portion was pulverized into fine powder by a grinder. Another portion was retained in its sliced form. Herb $(10 \mathrm{~g})$ was boiled in $200 \mathrm{~mL}$ double-distilled water. Volume of the decoction was maintained at 200 $\mathrm{mL}$ by adding water. Herbal decoction was collected after 30, 60 and 120 min of boiling.

Two multi-herb decoctions (i) ginseng and prepared aconite, and (ii) ginseng and ginger combination were prepared. (i) was prepared from Aconitum carmichaeli and $P$. ginseng according to the protocol from $A$ Repertory of Traumatology. A. carmichaeli $(9 \mathrm{~g})$ and $P$. ginseng $(12 \mathrm{~g})$ were cut into small pieces and boiled in $200 \mathrm{~mL}$ double-distilled water [27] for $60 \mathrm{~min}$. (ii) was prepared from Atractylodes macrocephala, P. ginseng, Glycyrrhiza uralensis and Zingiber officinale according to the protocol from Synopsis of Golden Chamber. Each herb (46.9 g) was boiled for $180 \mathrm{~min}$ in $1600 \mathrm{~mL}$ double-distilled water until $600 \mathrm{~mL}$ decoction remained [28].

\section{Treatment of decoction samples}

For each decoction sample collected at different times of boiling, large sediments were removed by MiniSpin centrifuge (Eppendorf, Hamburg, Germany). One portion of the supernatant was used for direct PCR and was regarded to be "crude DNA". Another portion was lyophilized, followed by DNA extraction using a QIAquick Nucleotide Removal kit (Qiagen, Hilden, Germany) according to manufacturer instructions for the single herb decoctions; modified cetyltrimethylammonium bromide (CTAB) DNA extraction (protocol 1) (Additional file 1) for the multi-herb decoctions; and modified CTAB DNA extraction (protocol 2) (Additional file 1) for the Korean Ginseng Chicken Stew. This portion was regarded to be "extracted DNA". Crude and extracted DNA were stored at $-20^{\circ} \mathrm{C}$ immediately and PCR analyses were carried out within one month.

\section{Sequence alignment and primer design}

Forty five DNA sequences of herbs were downloaded from the GenBank, National Center for Biotechnology Information (NCBI). These reference sequences were from $A$. carmichaeli trnH-psbA intergenic spacer, $A$. macrocephala ITS2, G. uralensis ITS2, $P$. ginseng and $P$. 
Table 1 Herbal samples*

\begin{tabular}{|c|c|c|c|c|}
\hline Scientific name & Herbal material name & Method of processing & Place of collection & Voucher \\
\hline Aconitum carmichaeli Debx. & Aconiti Lateralis Radix Praeparata (Fuzi) & Dried, salted & Sichuan, China & ICM 2014-3452 \\
\hline Atractylodes macrocephala Koidz. & Atractylodis Macrocephalae Rhizoma (Baizhu) & Dried, sliced & Zhejiang, China & ICM 2014-3449 \\
\hline \multirow[t]{3}{*}{ Panax ginseng C. A. Mey. } & \multirow[t]{3}{*}{ Ginseng Radix et Rhizoma (Renshen) } & \multirow[t]{3}{*}{ Dried } & \multirow[t]{3}{*}{ Jilin, China } & ICM 2005-2750 \\
\hline & & & & ICM 2005-2779 \\
\hline & & & & ICM 2014-3448 \\
\hline Glycyrrhiza uralensis Fisch. & Glycyrrhizae Radix et Rhizoma (Gancao) & Dried, sliced & Inner Mongolia, China & ICM 2014-3450 \\
\hline \multirow[t]{2}{*}{ Panax quinquefolius $\mathrm{L}$. } & \multirow[t]{2}{*}{ Panacis Quinquefolii Radix (Xiyangshen) } & \multirow[t]{2}{*}{ Dried } & \multirow[t]{2}{*}{ USA } & ICM 1713 \\
\hline & & & & ICM 901276 \\
\hline Zingiber officinale Rosc. & Zingiberis Rhizoma (Ganjiang) & Dried, sliced & Sichuan, China & ICM 2014-3451 \\
\hline
\end{tabular}

*All herbal samples were authenticated by Dr. David Tai-Wai Lau, Curator of the Shui-Ying Hu Herbarium, School of Life Sciences, The Chinese University of Hong Kong. In addition, DNA was extracted from the samples for DNA sequencing and results showed correct species identification.

quinquefolius $26 \mathrm{~S}-18 \mathrm{~S}$ intergenic spacer and $Z$. officinale ITS2 (Additional file 2). These multi-copy sequences are abundant in the herbs, available in GenBank, highly variable and can be used effectively for identification.

Sequence alignment was carried out using ClustalW2 (European Bioinformatics Institute, Hinxton, UK). Primers were designed with sequences shown in Table 2. Their melting temperatures, percentage of GC content, hairpin formation, as well as formation of self-dimers and hetero- dimers were determined by OligoAnalysis v3.1 (Integrated DNA Technologies, Coralville, IA, USA).

\section{PCR and DNA sequencing}

Different DNA loci were amplified by conventional PCR or multiplex PCR using the designed primers (Table 2). For conventional PCR, a $25 \mu \mathrm{L}$ reaction mixture comprising $1 \times$ PCR buffer (75 mM Tris, $\mathrm{pH} 8.8,20 \mathrm{mM}$ $\left(\mathrm{NH}_{4}\right)_{2} \mathrm{SO}_{4}, 1.5 \mathrm{mM} \mathrm{MgCl} 2,0.01 \%$ Tween 20), $0.2 \mathrm{mM}$

Table 2 Primers used for PCR amplification and sequencing

\begin{tabular}{|c|c|c|c|c|c|c|c|}
\hline Herbal species & $\begin{array}{l}\text { Primer } \\
\text { pair }\end{array}$ & $\begin{array}{l}\text { Primer } \\
\text { name }\end{array}$ & Direction & Primer sequence (5' to $\left.3^{\prime}\right)$ & $\begin{array}{l}\text { Amplicon } \\
\text { size (bp) }\end{array}$ & $\begin{array}{l}\text { Annealing } \\
\text { temperature }\left({ }^{\circ} \mathrm{C}\right)\end{array}$ & $\begin{array}{l}\text { Gene or } \\
\text { spacer region }\end{array}$ \\
\hline \multirow[t]{2}{*}{ A. carmichaeli } & 1 & Aca_F1 & Forward & GGTGCATGTCTGGCTTAG & 148 & 66 & $\operatorname{trnH}-\mathrm{psbA}$ \\
\hline & & Aca_R1 & Reverse & TCACCAAACCAACACCAATC & & & \\
\hline \multirow[t]{2}{*}{ A. macrocephala } & 2 & Ama_F1 & Forward & CGACCCGCGAACATGTAAC & 108 & 56 & ITS2 \\
\hline & & Ama_R1 & Reverse & CGAGGCCCCGATAGGTG & & & \\
\hline \multirow[t]{2}{*}{ G. uralensis } & 3 & Gur_F1 & Forward & ACAGACCGTTGCCCGAC & 106 & 57 & ITS2 \\
\hline & & Gur_R1 & Reverse & CAGTITGAGCCAACCGTGAG & & & \\
\hline \multirow[t]{11}{*}{ P. ginseng } & 4 & Pgi_F1 & Forward & GGCAGTTGGCTAATGAAAGGTTGTA & 88 & 64 & $26 S-18 S$ \\
\hline & & Panax_R1 & Reverse & AAGCACCGCTATGCGCGAA & & & \\
\hline & 5 & Pgi_F2 & Forward & TGAAAGGTTGTAATAGTTT & 249 & 48 & $26 S-18 S$ \\
\hline & & Pgi_R1 & Reverse & AATGAAAAGGAATGAAAG & & & \\
\hline & 6 & Pgi_F3 & Forward & ACGGTTGCTITTCCATCATTGTGT & 311 & 64 & $26 S-18 S$ \\
\hline & & Panax_R1 & Reverse & AAGCACCGCTATGCGCGAA & & & \\
\hline & 7 & Pgi_SPF1 & Forward & TGTCGGGCAAGGCCAAAAATG & 121 & 64 & $26 S-18 S$ \\
\hline & & Panax_R1 & Reverse & AAGCACCGCTATGCGCGAA & & & \\
\hline & 8 & Panax_F1 & Forward & GGTGCTITGAGTGCTGCTGA & 121 and 191 & 64 & $26 S-18 S$ \\
\hline & & Pgi_SPF1 & Forward & TGTCGGGCAAGGCCAAAAATG & & & \\
\hline & & Panax_R1 & Reverse & AAGCACCGCTATGCGCGAA & & & \\
\hline \multirow[t]{2}{*}{ P. ginseng, P. quinquefolius } & 9 & Panax_F1 & Forward & GGTGCTTTGAGTGCTGCTGA & 191 & 64 & $26 S-18 S$ \\
\hline & & Panax_R1 & Reverse & AAGCACCGCTATGCGCGAA & & & \\
\hline \multirow[t]{2}{*}{ Z. officinale } & 10 & Zof_F1 & Forward & GTAAAAGTCGGCAGTCGC & 106 & 65 & ITS2 \\
\hline & & Zof_R1 & Reverse & CACGCAGGGTCTCTTGAGG & & & \\
\hline
\end{tabular}


each of deoxynucleotide triphosphates, $1.5 \mathrm{mM} \mathrm{MgCl}$, $0.4 \mu \mathrm{M}$ of each primer, $10 \mathrm{ng}$ DNA sample and $10 \mathrm{U} / \mu \mathrm{L}$ of Taq DNA polymerase was used. Multiplex PCR was set up with $0.3 \mu \mathrm{M}$ forward conserved primer, $0.4 \mu \mathrm{M}$ forward $P$. ginseng-specific primer and $0.5 \mu \mathrm{M}$ reverse conserved primer (primer pair 8 in Table 2). Reactions were conducted by a Veriti Thermal Cycler (Applied Biosystems, Foster City, CA, USA) through 35 cycles of $95^{\circ} \mathrm{C}$ for $30 \mathrm{~s}$, at the specific annealing temperature of each primer pair (Table 2) for $20 \mathrm{~s}$ and $72^{\circ} \mathrm{C}$ for $30 \mathrm{~s}$. Amplicons were electrophoresed and visualized on 3\% agarose gels stained with ethidium bromide. Amplicons were purified by a DNA Gel Extraction kit (Biomed, Beijing, China) followed by DNA sequencing (Beijing Genomics Institute, Hong Kong, China). Percentage maximum coverage and identity between amplified and reference DNA sequences were determined by the Basic Local Alignment Search Tool (BLAST) of NCBI.

\section{DNA concentration and statistical analyses}

Extracted DNA was diluted so that its concentration was the same as that in the decoction. DNA concentration was measured using a Qubit 2.0 Fluorometer (Invitrogen, Carlsbad, CA, USA) and presented as the mean \pm standard deviation. Differences between boiling times were assessed by one-way analysis of variance. Differences between sliced and pulverized samples at the same boiling time were analyzed by the two-sample $t$ test. $P<0.05$ was considered statistically significant.

\section{Results}

\section{PCR products and DNA concentration in single herb decoction}

We investigated if a $191 \mathrm{bp}$ DNA of the $P$. ginseng 26S$18 \mathrm{~S}$ intergenic spacer region could be amplified from the single herb $P$. ginseng decoction prepared by boiling sliced or pulverized samples for 30,60 and $120 \mathrm{~min}$. With the concentration of the crude and extracted DNA adjusted to that in the original decoction, visible PCR products were found in crude and extracted DNA with samples boiled for $30 \mathrm{~min}$. More PCR product was obtained in pulverized samples boiled for $60 \mathrm{~min}$ (Figure 1A), and there was a significant increase in DNA released into the decoction in pulverized samples for each boiling time compared with sliced samples (30 min: $P=0.0280$; 60 min: $P=0.0319 ; 120$ min: $P=0.0479)$ (Figure 1B). A visible PCR product was not observed upon boiling for 120 min, although it was a time at which the highest DNA concentration was measured.

\section{Size of PCR product with boiling time}

We investigated the relationship between boiling time and the size of amplifiable DNA. DNA fragments with sizes (in bp) of 88, 121, 191, 249 and 311 were amplified.
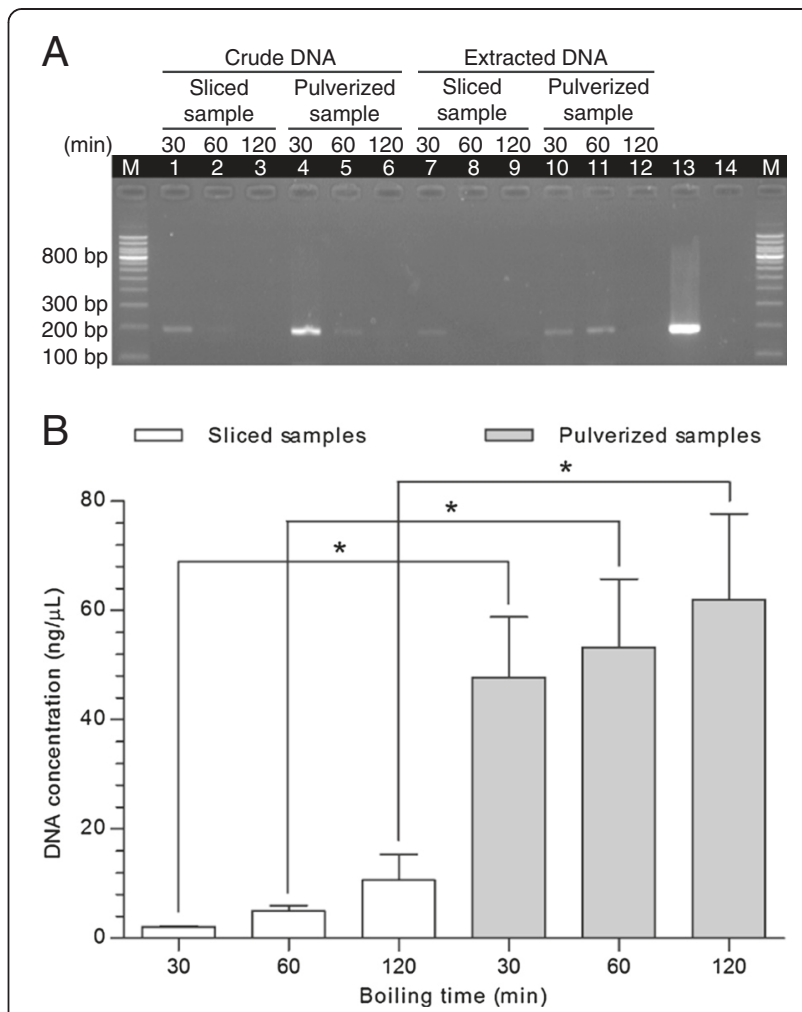

Figure 1 PCR amplification and DNA concentration in decoction with sliced or pulverized sample at different times of boiling. (A) P. ginseng sample was sliced (lanes 1-3, 7-9) or pulverized (lanes 4-6, 10-12) and boiled for 30 min (lanes 1, 4, 7, 10), 60 min (lanes 2, 5, 8, 11) and 120 min (lanes 3, 6, 9, 12). Crude DNA (lanes 1-6) and extracted DNA with concentration adjusted to that in the original decoction (lanes 7-12) were amplified by primer pair 9. Lane 13 is the positive control with DNA from P. ginseng and lane 14 is the negative control without DNA. Lane M represents the DNA size ladder. (B) The concentration of extracted $P$. ginseng DNA was adjusted to make it similar to that in the original decoction and measured by Qubit 2.0 Fluorometer. Water was used as blank and the data represent mean \pm standard deviation $(n=3)$. Difference between boiling time was analyzed by one-way analysis of variance. Difference between sliced and pulverized samples at the same boiling time was analyzed by two sample $t$ test $\left({ }^{*} p<0.05\right)$.

For pulverized samples boiled for 30 and $60 \mathrm{~min}$, DNA fragments of size 88-311 bp were amplified (Figure 2A and $\mathrm{B}$ ). However, only short PCR products with sizes ranging from 88-121 bp were amplified for samples boiled for $120 \mathrm{~min}$ (Figure 2C).

\section{Multiplex PCR for differentiation between ginseng and American ginseng}

Multiplex PCR was developed to differentiate $P$. ginseng from $P$. quinquefolius. PCR master mixes involved one pair of conserved primers for $P$. ginseng and $P$. quinquefolius (Panax_F1 and Panax_R1), and a forward P. ginsengspecific primer (Pgi_SPF1) region for pairing with the same reverse conserved primer (Panax_R1) (Additional file 3 ). Three nucleotides at the 3 ' end of the 21 nucleotide 


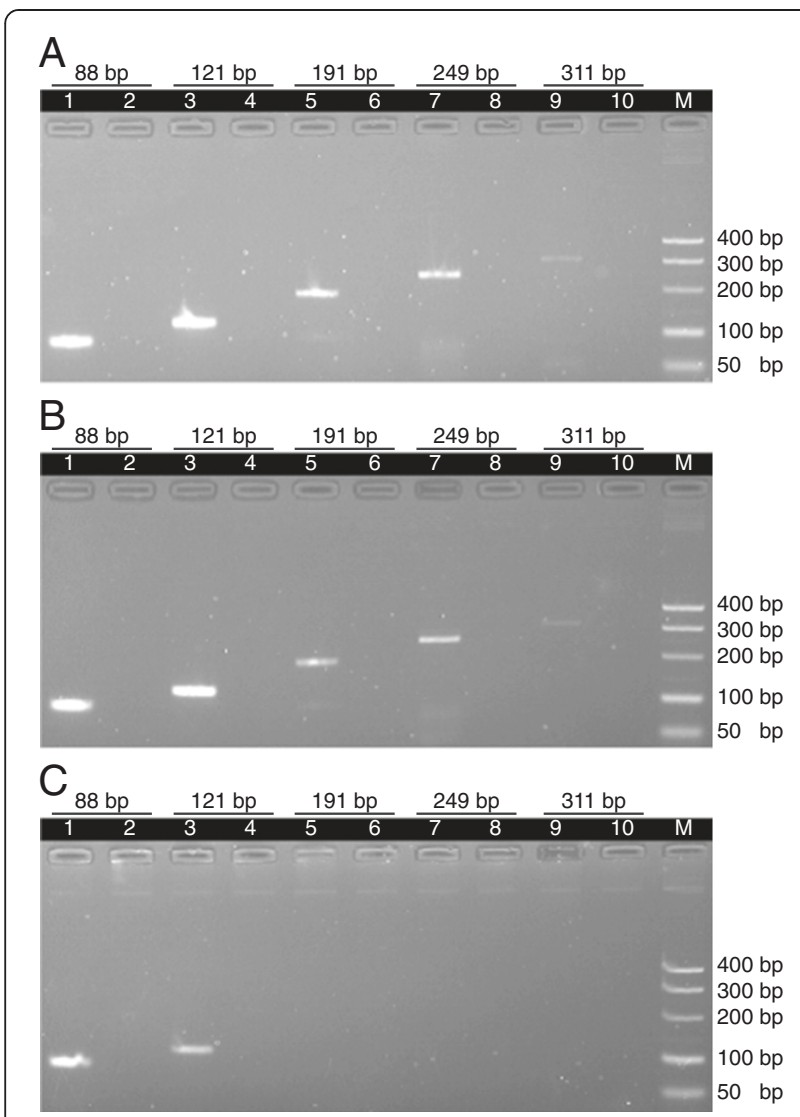

Figure 2 DNA degradation with time of boiling. Pulverized $P$. ginseng sample was boiled for (A) $30 \mathrm{~min},(\mathbf{B}) 60 \mathrm{~min}$ and (C) 120 min. The extracted DNA was amplified by PCR to produce $88 \mathrm{bp}$ (lane 1) using primer pair 4, 121 bp (lane 3) using primer pair 7, 191 bp (lane 5) using primer pair 9, $249 \mathrm{bp}$ (lane 7) using primer pair 5 and 311 bp (lane 9) using primer pair 6. Lanes 2, 4, 6, 8, 10 are negative controls of its previous lanes without decoction DNA. Lane $\mathrm{M}$ represents the DNA size ladder.

forward $P$. ginseng-specific primer were different from those of the DNA sequence of $P$. quinquefolius (Figure 3A). As a result, the $191 \mathrm{bp}$ amplicon was found in $P$. ginseng and $P$. quinquefolius decoction and the $121 \mathrm{bp}$ amplicon was found only in the $P$. ginseng decoction (Figure $3 \mathrm{~B}$ and C). However, the 191 bp amplicon was not found in the decoction boiled for $120 \mathrm{~min}$ (Figure 3B and C) due to DNA degradation (Figure $2 \mathrm{C}$ ).

\section{Identification of herbs used in multi-herb decoctions and commercial soup}

In a decoction involved two herbs (ginseng and prepared aconite), A. carmichaeli (148 bp) and P. ginseng (121 bp) could be amplified in extracted DNA with samples boiled for 30 and $60 \mathrm{~min}$ (Figure 4A). In another decoction involved four herbs (ginseng and ginger combination), A. macrocephala (108 bp), G. uralensis (106 bp), $P$. ginseng $(121 \mathrm{bp})$ and $Z$. officinale $(106 \mathrm{bp})$ were amplified in extracted DNA with samples boiled for $180 \mathrm{~min}$

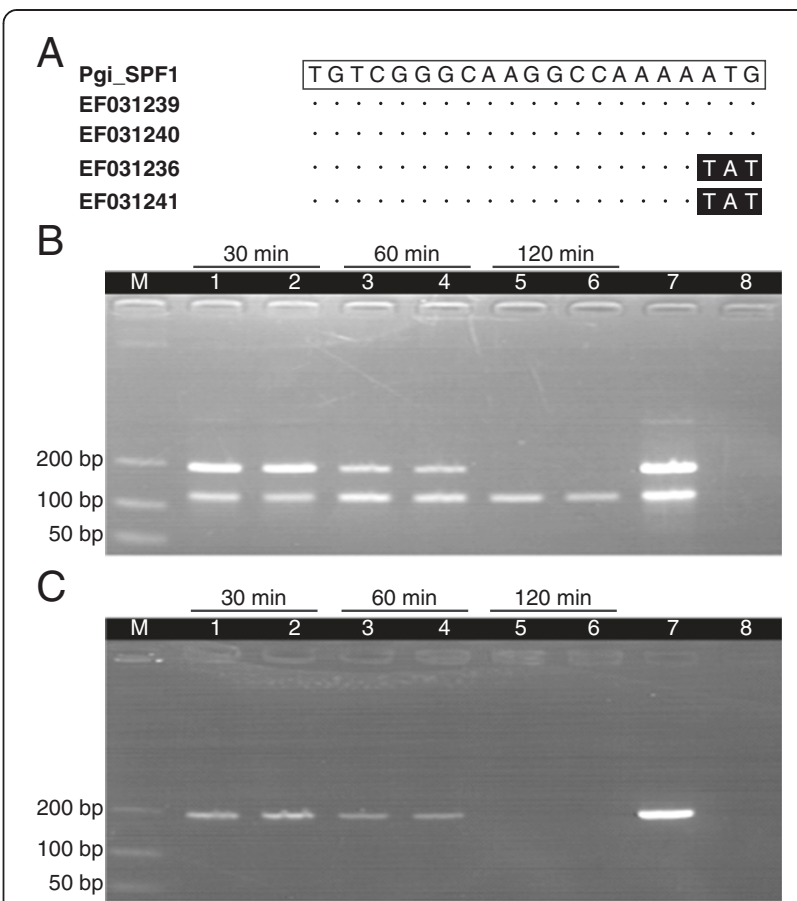

Figure 3 Multiplex PCR in differentiation of ginseng and American ginseng. (A) Nucleotide sequences of the forward $P$. ginseng-specific primer (Pgi_SPF1) with comparison to the aligned reference sequences of $P$. ginseng (Genbank accession number: EF031239, EF031240) and P. quinquefolius (Genbank accession number: EF031236, EF031241). Open box indicates the primer sequence, dots and closed boxes indicate nucleotides identical and different from the primer sequence, respectively. (B and $\mathbf{C}$ ) Amplification of the extracted DNA from two vouchers of pulverized (B) P. ginseng (ICM 2005-2750, ICM 2005-2779) and (C) P. quinquefolius (ICM 1713, ICM 901276) samples by multiplex PCR using primer pair 8. Samples in herbal decoction were boiled for 30 min (lanes 1-2), 60 min (lanes 3-4) and 120 min (lanes 5-6), respectively. Lane 7 is the positive control with DNA from the concerned herbal sample and lane 8 is the negative control without DNA. Lane M represents the DNA size ladder.

(Figure 4B-E). We could also amplify the $P$. ginseng component in Korean Ginseng Chicken Stew after DNA was extracted (Figure 5).

\section{Discussion}

In the present study, DNA released into the decoction by boiling could be amplified by PCR. BLAST analyses of these amplicons showed $\geq 99 \%$ coverage and identity between the amplified and reference sequences (Additional file 4).

Pulverization of the sample increased the yield of DNA released into the decoction (Figure $1 \mathrm{~B}$ ) due to the increase in the surface area of the sample. The highest DNA concentration was measured in the decoction boiled for 120 min but a PCR product was not observed (Figure 1A). An increase in the duration of heat treatment can cause a higher degree of DNA fragmentation in meat samples 


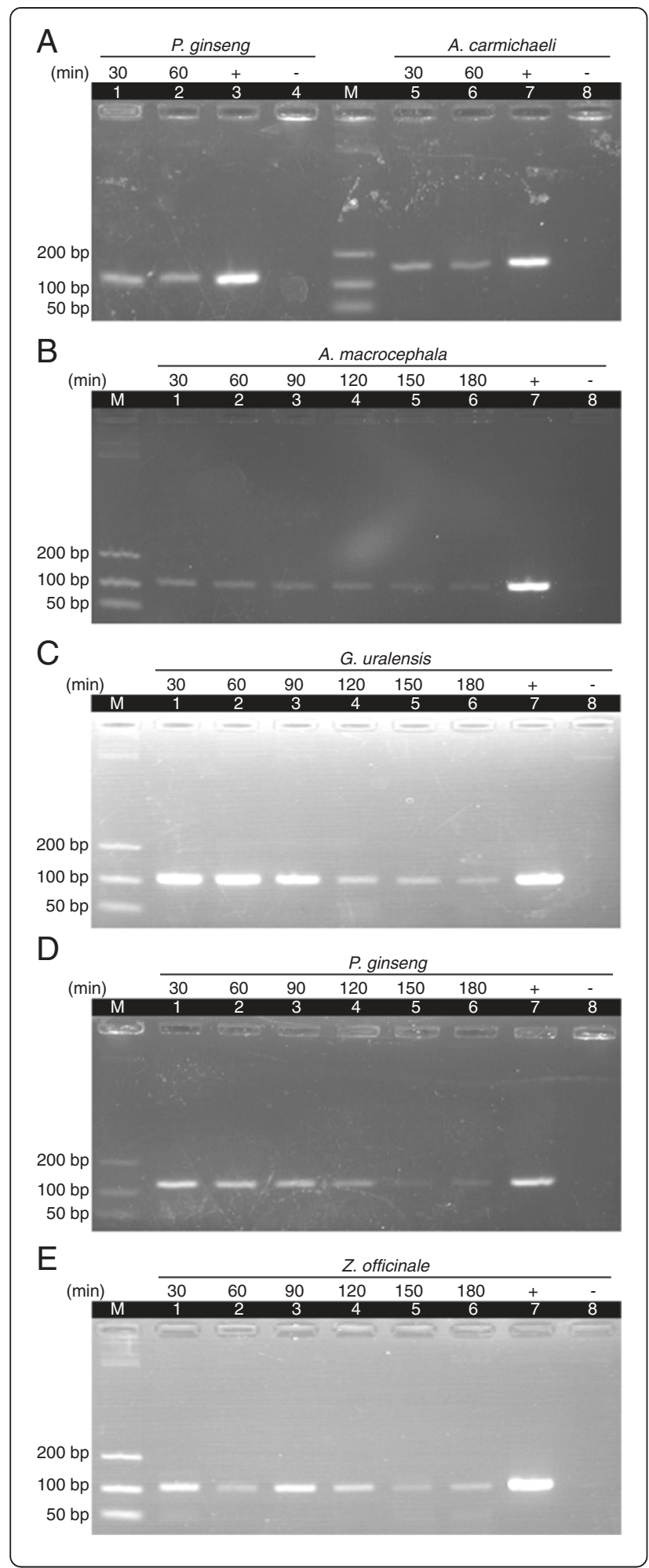

\section{Figure 4 PCR amplification of extracted DNA in the}

prescriptions. (A) Two herbs decoction: Decoction of Ginseng and Prepared Aconite. The prescription was boiled for 30 min (lanes 1 and 5) and 60 min (lanes 2 and 6). Extracted DNA was amplified by primer pair 7 (lanes 1-2) for $P$. ginseng and primer pair 1 (lanes 5-6) for $A$. carmichaeli. Lanes 3 and 7 are positive controls with DNA from the concerned herbal sample and lanes 4 and 8 are negative controls without DNA. (B-E) Four herbs decoction: Ginseng and Ginger Combination. The prescription was boiled for 30 min (lane 1), 60 min (lane 2), 90 min (lane 3), 120 min (lane 4), 150 min (lane 5) and $180 \mathrm{~min}$ (lane 6). Primers specific for (B) A. macrocephala (Primer pair 2), (C) G. uralensis (Primer pair 3), (D) P. ginseng (Primer pair 7) and (E) Z. officinale (Primer pair 10) were used to amplify the decoction DNA. Lane 7 is positive control with DNA from the concerned herbal sample and lane 8 is negative control without DNA. Lane M represents the DNA size ladder.

[29]. This phenomenon might also be the case in decoction, resulting in a less amplifiable DNA template that is intact. We confirmed this hypothesis by amplifying DNA of sizes ranging from 88-311 bp. Only short PCR products of $\leq 121$ bp were observed with 120 min boiling (Figure 2C). Therefore, the amplicon to be studied in the decoction should be short. Sometimes this requirement may mean that the ability to differentiate between species is sacrificed. In our case, because of limited sequences in GenBank, our primers designed for A. carmichaeli (primer pair 1 in Table 2) and G. uralensis (primer pair 3 in Table 2) were specific at the genus level. Other primers had specificity at the species level (Additional file 4).

The PCR product was detected by amplifying crude DNA in the single herb decoction directly (Figure 1A). The chemicals released from herbs might not be detrimental to PCR in certain cases. This phenomenon increased the efficiency of authentication because time-consuming DNA extraction procedures could be omitted.

In the market, it is common to find cultivated $P$. ginseng as an adulterant of $P$. quinquefolius. These two herbs have different pharmacological effects and chemical

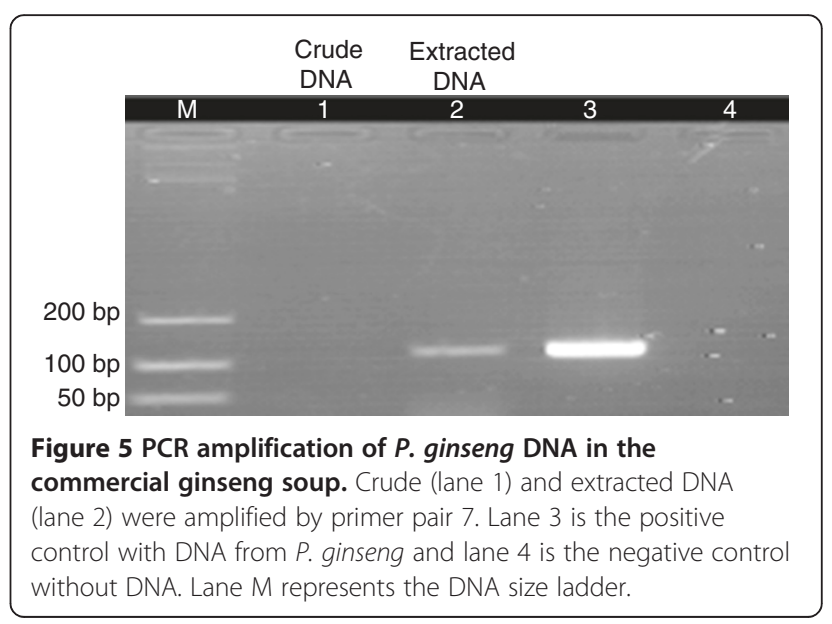


compositions [30,31]. We investigated the possibility of differentiating $P$. ginseng and $P$. quinquefolius in decoctions by multiplex PCR. PCR master mixes involved one pair of conserved primers for $P$. ginseng and $P$. quinquefolius, and a forward $P$. ginseng-specific primer (Additional file 3). The $191 \mathrm{bp}$ conserved amplicon was amplified and served as the positive control to ensure sufficient intact DNA fragments presented in the decoction. There were three nucleotide mismatches with the DNA sequence of $P$. quinquefolius at the $3^{\prime}$ end of the forward $P$. ginsengspecific primer sequence (i.e., nearly $15 \%$ mismatch) (Figure 3A), which made the primer sufficiently specific for producing the $121 \mathrm{bp} P$. ginseng-specific PCR product (Figure 3B). This approach may be explored for differentiating between genuine and adulterant herbs in a decoction and, if coupled to quantitative PCR, for finding the ratio of the two herbs.

Herbal prescriptions usually consist of more than one herb. Two classical ginseng prescriptions (ginseng and prepared aconite, ginseng and ginger combination) and a commercial ginseng soup were tested to illustrate the possibility of identification of herbs by DNA markers in multi-herb decoctions. Results showed that DNA fragments of the relevant herbal ingredients were amplified (Figures 4 and 5).

Some of the herbs used in the prescriptions were dried and some were even processed (Table 1). In comparison with fresh materials, carrying out molecular authentication for dried and processed herbal materials is difficult because DNA is degraded or interacts with other chemicals. Several protocols have been developed to facilitate DNA extraction of different herbal samples: silica binding [32], salting-out precipitation [33], magnetic beads binding, such as ChargeSwitch gDNA Plant Kit (Invitrogen, Carlsbad, CA, USA) and anion exchange purification, such as Genomic Tip 20/G (Qiagen, Hilden, Germany) [34]. There are also reports to extract PCR amplifiable DNA from maize, soy bean [35], fish derived food products [36] and rice wine [37]. Our study shows the presence of PCR amplifiable DNA fragments of herbal materials in the aqueous solution after boiling. This phenomenon may be investigated further for other herbal decoctions.

\section{Conclusions}

DNA could be amplified from extensively boiled ginseng decoctions, multi-herb decoctions and commercial soup although DNA degradation was critical to successful PCR.

\section{Additional files}

Additional file 1: Modified CTAB extraction protocols.

Additional file 2: GenBank accession numbers of herbal species for primer design.
Additional file 3: Comparison of the aligned $26 \mathrm{~S}-18 \mathrm{~S}$ sequences of $P$. ginseng and $P$. quinquefolius for multiplex PCR primer design.

Additional file 4: DNA sequences of amplicons and its percentage coverage and identity to NCBI GenBank DNA sequences.

\section{Abbreviations}

BLAST: Basic Local Alignment Search Tool; CTAB: cetyltrimethylammonium bromide; DNA: Deoxyribonucleic acid; ITS2: Ribosomal internal transcribed spacer 2; NCBI: National Center for Biotechnology Information;

PCR: Polymerase chain reaction.

Competing interests

The authors declare that they have no competing interests.

\section{Authors' contributions}

YTL and ML conceived and designed the study. YTL performed experiments and data analyses. All authors wrote, read and approved the manuscript.

\section{Acknowledgements}

Thanks are due to Mr. Ka-Lok Wong and Dr. Li-Li Jiang for helpful discussion and Dr. David Tai-Wai Lau, Curator of the Shiu-Ying Hu herbarium, School of Life Sciences, The Chinese University of Hong Kong for authenticating the herbs by organoleptic characteristics.

Received: 29 August 2014 Accepted: 20 January 2015

Published online: 30 January 2015

\section{References}

1. But PP. Herbal poisoning caused by adulterants or erroneous substitutes. J Trop Med Hyg. 1994;97:371-4.

2. Chen J, Chen L, An Z, Shi S, Zhan Y. Non-technical causes of fakes existing in Chinese medicinal material markets. J Chin Med Mater. 2002;25:516-9.

3. Fung HT, Lam KK, Lam SK, Wong OF, Kam CW. Two cases of Gelsemium elegans Benth. poisoning. Hong Kong J Emerg Med. 2007;14:221-4.

4. Gilbert N. Regulations: herbal medicine rule book. Nature. 2011;480:598-9.

5. Sakurai M. Perspective: herbal dangers. Nature. 2011;480:S97.

6. Tomlinson B, Chan TY, Chan JC, Critchley JA, But PP. Toxicity of complementary therapies: an eastern perspective. J Clin Pharmacol. 2000:40:451-6.

7. Wang $\mathrm{H}$, Kim MK, Kwon WS, Jin H, Liang Z, Yang DC. Molecular authentication of Panax ginseng and ginseng products using robust SNP markers in ribosomal external transcribed spacer region. J Pharm Biomed Anal. 2011;55:972-6.

8. Coghlan ML, Haile J, Houston J, Murray DC, White NE, Moolhuijzen P, et al Deep sequencing of plant and animal DNA contained within traditional Chinese medicines reveals legality issues and health safety concerns. PLoS Genet. 2012;8:e1002657.

9. Wong L, Liang Z, Chen H, Zhao Z. Authentication of Chinese Materia Medica decoction dregs, part 1: comparison of morphological and microscopic features of four Chinese Materia Medica before and after decoction. Microsc Res Tech. 2010;74:320-8.

10. Wong L, Liang Z, Chen H, Zhao Z. Authentication of Chinese Materia Medica decoction dregs. Part II: comparison before and after decoction of four Chinese Materia Medica that mainly comprise storage tissue. Microsc Res Tech. 2012;75:164-75.

11. Wen J, Qiao Y, Xiong Z, Li F. Simultaneous determination of seven constituents in Si-Ni-San decoction and a compatibility comparison study using HPLC-UV. Nat Prod Res. 2014;28:1-5.

12. Shaw PC, Jiang RW, Wong KL, But Paul PH. Health food and medicine: combined chemical and molecular technologies for authentication and quality control. In: Ebeler SE, Takeoka GR, Winterhalter P, editors. Authentication of food and wine. Volume 952. Washington, DC: American Chemical Society; 2006. p. 305-24.

13. Chan PH, Zhang WL, Cheung CY, Tsim KW, Lam H. Quality control of danggui buxue tang, a traditional Chinese medicine decoction, by (1)H-NMR metabolic profiling. Evid Based Complement Alternat Med. 2014;2014:567893.

14. Shaw PC, Ngan FN, But PP, Wang J. Molecular marker in Chinese medicinal materials. In: Shaw PC, Wang J, But PP, editors. Authentication of Chinese 
medicinal materials by DNA technology. Singapore: World Scientific; 2002. p. 1-23.

15. Xin T, Yao H, Gao H, Zhou X, Ma X, Xu C, et al. Super food Lycium barbarum (Solanaceae) traceability via an internal transcribed spacer 2 barcode. Food Res Int. 2013;54:1699-704.

16. Chen G, Wang XL, Wong WS, Liu XD, Xia B, Li N. Application of 3' untranslated region (UTR) sequence-based amplified polymorphism analysis in the rapid authentication of Radix astragali. J Agric Food Chem. 2005;53:8551-6.

17. Zhu S, Fushimi H, Komatsu K. Development of a DNA microarray for authentication of ginseng drugs based on 185 rRNA gene sequence. J Agric Food Chem. 2008;56:3953-9.

18. LeRoy A, Potter E, Woo HH, Heber D, Hirsch AM. Characterization and identification of alfalfa and red clover dietary supplements using a PCR-based method. J Agric Food Chem. 2002;50:5063-9.

19. Zhang YB, Shaw PC, Sze CW, Wang ZT, Tong Y. Molecular authentication of Chinese herbal materials. J Food Drug Anal. 2007;15:1-9.

20. Chen S, Pang X, Song J, Shi L, Yao H, Han J, et al. A renaissance in herbal medicine identification: from morphology to DNA. Biotechnol Adv. 2014;32:1237-44.

21. State Pharmacopoeia Commission. Pharmacopoeia of the People's Republic of China: Online supplementary note 2 [http://www.chp.org.cn/export/sites/ chp/resource/publicity/100805/2/2.pdf]

22. State Pharmacopoeia Commission. Pharmacopoeia of the People's Republic of China: part 1. Beijing: China Medical Science Press; 2010.

23. Horreo JL, Ardura A, Pola IG, Martinez JL, Garcia-Vazquez E. Universal primers for species authentication of animal foodstuff in a single polymerase chain reaction. J Sci Food Agric. 2013;93:354-61.

24. Demirhan $Y$, Ulca P, Senyuva $H Z$. Detection of porcine DNA in gelatine and gelatine-containing processed food products-Halal/Kosher authentication. Meat Sci. 2012;90:686-9.

25. Michelini E, Cevenini L, Mezzanotte L, Simoni P, Baraldini M, De Laude L, et al. One-step triplex-polymerase chain reaction assay for the authentication of yellowfin (Thunnus albacares), bigeye (Thunnus obesus), and skipjack (Katsuwonus pelamis) tuna DNA from fresh, frozen, and canned tuna samples. J Agric Food Chem. 2007;55:7638-47.

26. LV P, Zhou X, You J, Ye BC, Zhang Y. Extraction of trace amount of severely degraded DNA. Z Naturforsch [C]. 2009;64:581-9.

27. Xue J. Zheng Ti Lei Yao: Part 2. Shanghai: Shanghai Wei Sheng Chu Ban She; 1957.

28. Chang CC. Chin Kuei Yao Lueh : Prescriptions from the Golden Chamber. Los Angeles: Oriental Arts Healing Institute; 1983.

29. Sakalar E, Abasiyanik MF, Bektik E, Tayyrov A. Effect of heat processing on DNA quantification of meat species. J Food Sci. 2012;77:N40-1.

30. Chen CF, Chiou WF, Zhang JT. Comparison of the pharmacological effects of Panax ginseng and Panax quinquefolium. Acta Pharmacol Sin. 2008;29:1103-8.

31. Choi KT. Botanical characteristics, pharmacological effects and medicinal components of Korean Panax ginseng C A Meyer. Acta Pharmacol Sin. 2008:29:1109-18.

32. Ivanova N, Fazekas A, Hebert PN. Semi-automated, membrane-based protocol for DNA isolation from plants. Plant Mol Biol Rep. 2008;26:186-98.

33. Kang $\mathrm{H}$, Cho $\mathrm{Y}$, Yoon U, Eun M. A rapid DNA extraction method for RFLP and PCR analysis from a single dry seed. Plant Mol Biol Rep. 1998;16:1-9.

34. Sarkinen T, Staats M, Richardson JE, Cowan RS, Bakker FT. How to open the treasure chest? Optimising DNA extraction from herbarium specimens. PLoS One. 2012:7:e43808.

35. Di Bernardo G, Del Gaudio S, Galderisi U, Cascino A, Cipollaro M. Comparative evaluation of different DNA extraction procedures from food samples. Biotechnol Prog. 2007;23:297-301.

36. Kitaoka M, Okamura N, Ichinose $\mathrm{H}$, Goto M. Detection of SNPs in fish DNA: application of the fluorogenic ribonuclease protection (FRIP) assay for the authentication of food contents. J Agric Food Chem. 2008;56:6246-51.

37. Ohtsubo K, Suzuki K, Haraguchi K, Nakamura S. Novel method for preparation of the template DNA and selection of primers to differentiate the material rice cultivars of rice wine by PCR. J Biochem Biophys Methods. 2008;70:1020-8.

\section{Submit your next manuscript to BioMed Central and take full advantage of:}

- Convenient online submission

- Thorough peer review

- No space constraints or color figure charges

- Immediate publication on acceptance

- Inclusion in PubMed, CAS, Scopus and Google Scholar

- Research which is freely available for redistribution 